\title{
INTERFUEL: FAST -- Fueling Center and EVSE Reporting Process Changes
}

\section{Ron Stewart}

July 2020

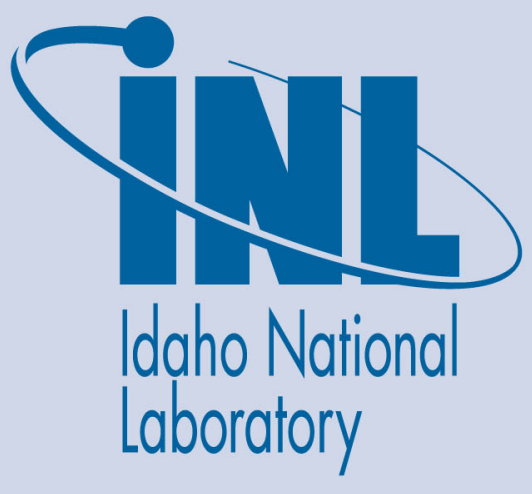

The INL is a U.S. Department of Energy National Laboratory operated by Battelle Energy Alliance 


\title{
INTERFUEL: FAST -- Fueling Center and EVSE Reporting Process Changes
}

\author{
Ron Stewart
}

July 2020

\begin{abstract}
Idaho National Laboratory Idaho Falls, Idaho 83415
\end{abstract}

http://www.inl.gov

\author{
Prepared for the \\ U.S. Department of Energy \\ Office of Energy Efficiency and Renewable Energy, Office of Nuclear Energy \\ Under DOE Idaho Operations Office \\ Contract DE-AC07-05ID14517, DE-AC07-05ID14517
}




\section{FAST: Fueling Center \& EVSE Reporting Process Changes}

INTERFUEL - July 8, 2020

Ron Stewart

FAST Support Team

Fu Idaho National Laboratory 


\section{FAST and Fleet Data Collection}

- Vehicles and operational data

- Vehicle attributes, costs, miles, fuel consumption

- Fleet planning data

- Future-year plans for acquisitions and disposal

- Budget projections

- Results of vehicle allocation methodology (VAM) studies

- EPAct 2005 Section 701 Waiver Requests

- Now part of primary data call October-December

- Fleet fueling center information

- Electric vehicle supply equipment (EVSE) inventory 


\section{Underlying Requirements for Infrastructure-related Information}

- Energy Independence and Security Act (EISA) of 2007, Section 246

- Requires federal fueling centers distributing $>100 \mathrm{~K}$ gal of petroleum fuel annually to also have renewable fuel infrastructure

- Fixing America's Surface Transportation (FAST) Act of 2015

- Authorizes agencies to install EV charging stations for POVs

- Requires agencies to collect fees to recover costs of this EVSE

- CEQ guidance direct agency CSOs to work with fleet managers to report on implementation of workplace charging

- GSA's Public Buildings Service annual report to Congress due December 4

- Energy Policy Act (EPAct) of 2005, Section 701

- Alt fuel vehicles (AFVs) must consume alt fuels

- Agencies may request waivers for AFVs without access to fuel

- Waiver review process relies on knowing where federal fueling infrastructure is located (in addition to other infrastructure)

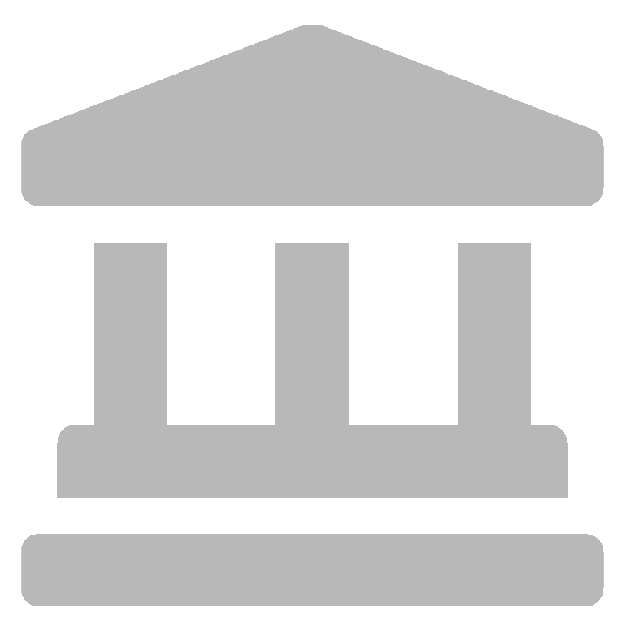




\section{Previous Reporting Processes}

- Information about fueling centers:

- Single agency-level FAST submission each year

- Due June 30

- Covers agency-defined 12-month period

- Each station described by

- Name and location

- Current status (open / closed)

- Types and volumes of fuel

- Access information: who can use center?

- EISA Sec. 246 compliance attributes

- Submitted via data entry form or MS Excel worksheet 


\section{Previous Reporting Processes}

- Information about electric vehicle supply equipment (EVSE):

- Single agency-level FAST submission each year

- Due December 15

- EVSE inventory for previous fiscal year

- EVSE described by

- Name and location

- New or existing?

- \# and type of EVSE

- Designation of use (employee, fleet, public)

- Costs (installation, hardware, usage fees)

- Submitted via MS Excel worksheet 


\section{New Approach to Reporting}

- Single combined submission due Nov. 15 (tentative)

- Fueling centers

- Name and location

- Status (new, existing, closed)

- Types of fuel distributed

- Indication of $>100 \mathrm{~K}$ gal of petroleum

- No longer collecting fuel volumes!

- Other EISA 246 compliance attributes

- EVSE inventory

- Name and location

- Status (new, existing, closed)

- \# and type of EVSE at location

- Costs and usage fees

- Access 


\section{New Approach to Reporting}

- Submitted as MS Excel worksheet

- Separate sheets with instructions, data collection sheets, examples

- DOE will assign unique "station ID"

- Assigned to each fueling center and EVSE location

- Station ID + status will simplify year-to-year reporting

- Submission each year will serve as starting point for following year's submission 


\section{New Approach to Reporting: Process and Timeline}

- NLT August 15, 2020: New Excel template released

- Separate sheets with instructions, data collection sheets, examples

- Agencies can begin assembling data for fall submission

- Agencies can request (mostly) compatible versions of most recent fuel center and EVSE submissions as starting point from FAST team

- November 15, 2020: FY 2020 submission due

- Describes all agency fueling centers and EVSE as of end of FY 2020

- After submission

- DOE assigns station IDs

- DOE uses information as part of revamped EPAct 701 waiver review process

- August 1, 2021: Agency can retrieve FY 2021 Excel template

- Will be based on FY 2020 submission + DOE-assigned IDs 


\section{Summary}

- Combined fueling center + EVSE submission due November 15

- Same timeframe as previous EVSE submission

- Retires past June submission (fueling center data, 701 waivers)

- Simplifies fueling center data

- No more fuel volumes!

- Simplifies and improves year-to-year reporting

- Collects all fueling infrastructure data

- ... in more consistent manner

- ... covering same time period

- ... at the same time 


\section{While We Have Your Attention...}

- Conversations with several organizations during Spring 2020

- Ideas to ease / simplify / improve VLD reporting

\section{- Changes coming over the next few months}

- Update and combine VLD reference documents into unified reference

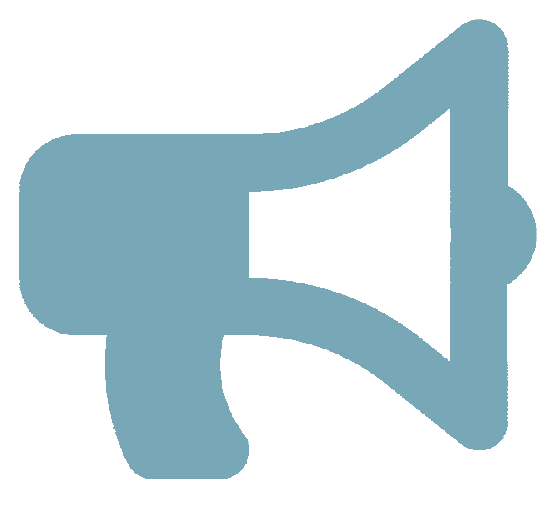

- Tune flagging rules

- Identify plug-in hybrid vehicles without electricity consumption

- Reduce some of the flagging noise

- Example: Only flag year-to-year changes in vehicle attributes if they are significant

- Tune the post-submission review metrics

- Example: Better identification of unexpected changes in costs 


\section{While We Have Your Attention...}

- Changes coming over the next few months

- Improvements / updates to FAST reports

- Provide some of the post-submission review metrics

- Improve usability / make them easier to understand

- Ability to export submitted vehicle-level data

- Other improvements

- Continuing focus on responsiveness / speed

- Ability to retrieve larger results from FAST's query tool

- New FAST support email address

- FASTsupport@inl.gov 


\section{FAST Program Points of Contact}

- DOE Federal Energy Management Program (FEMP)

Jay Wrobell

jay.wrobell@ee.doe.gov

Kendall Kam

kendall.kam@ee.doe.gov

- GSA Office of Government-wide Policy (OGP)

Jim Vogelsinger

james.vogelsinger@gsa.gov

Patrick McConnell

patrick.mcconnell@gsa.gov

- EIA Office of Energy Consumption \& Efficiency Statistics

Cynthia Sirk

cynthia.sirk@eia.gov

- INL FAST Support Team

Ron Stewart

$$
\text { ron.stewart@inl.gov }
$$

- Tim Raczek

timothy.raczek@inl.gov

- Michelle Kirby

michelle.kirby@inl.gov

- Team Contact Information FASTsupport@inl.gov @FASTdevs

- NREL Federal Fleet Program

- Cabell Hodge

cabell.hodge@nrel.gov

- Mark Singer

mark.singer@nrel.gov 